\title{
A call to maximize impact of the SUPPORT for Patients and Communities Act through standard inclusion of opioid use disorder treatment curricula in medical schools
}

This article was published in the following Dove Press journal:

Advances in Medical Education and Practice

\author{
Aaron Shapiro' \\ Lisa R Villarroel ${ }^{2}$ \\ Paul George 3,4 \\ 'The Warren Alpert Medical School of \\ Brown University, Providence, RI, USA; \\ ${ }^{2}$ Division of Public Health Preparedness, \\ Arizona Department of Health Services, \\ Phoenix, AZ, USA; ${ }^{3}$ Department of \\ Family Medicine, The Warren Alpert \\ Medical School of Brown University, \\ Providence, RI, USA; ${ }^{4}$ Office of Medical \\ Education, The Warren Alpert Medical \\ School of Brown University, Providence, \\ $\mathrm{RI}$, USA
}

\begin{abstract}
Physicians who want to prescribe buprenorphine to treat opioid use disorder require a waiver established by the Drug Addiction Treatment Act (DATA) of 2000, often through completion of an eight-hour training course. This is an issue for a number of reasons, including that opioid overdose deaths continue to rise nationally. However, on October 24, 2018, the SUPPORT (Substance Use-Disorder Prevention that Promotes Opioid Recovery and Treatment) for Patients and Communities Act was signed into law. This bill allows any physician who graduates in good standing from an allopathic or osteopathic medical school in the United States that incorporates necessary material around opioid misuse in their standard curriculum, without need for any additional training, to prescribe buprenorphine. This perspective piece describes why this is an important first step and what more needs to be done within medical education to combat the opioid epidemic.
\end{abstract}

Keywords: opioid use disorder, medical education, buprenorphine waiver

\section{Context}

On October 24, 2018, the SUPPORT (Substance Use-Disorder Prevention that Promotes Opioid Recovery and Treatment) for Patients and Communities Act was signed into law. Prior to this bill's passage, physicians who wanted to prescribe buprenorphine to treat opioid use disorder could only do so by receiving a waiver established by the Drug Addiction Treatment Act (DATA) of 2000, often requiring completion of an eight-hour training course. This waiver was initially intended to expand access to medical treatment for opioid use disorder beyond methadone, but, as we discuss here, has ultimately proven to be a unique and harmful barrier to providing care to those in need. One component of the SUPPORT Act intends to decrease this barrier by providing eligibility for the waiver to any physician who graduates in good standing from an allopathic or osteopathic medical school in the United States that incorporates the necessary material in their standard curriculum, without need for any additional training. ${ }^{1}$ As of early summer 2019, a process now exists in which medical schools can go through the American Academy of Addiction Psychiatry to certify their curriculum as meeting DATA waiver requirements. It is critical for medical educators to be aware of this change and ensure that their curricula contain the necessary training so that every graduating medical student in the United States is eligible for the waiver. Furthermore, medical
Correspondence: Aaron Shapiro Department of Internal Medicine Montefiore Medical Center, 305 East I6Ist Street, Bronx, New York, NY I045I, USA

Email aashapiro@montefiore.org 
educators must lead the effort to train a new generation of physicians that is ready to treat opioid use disorder with the urgency and skill that the opioid epidemic merits.

Historically, opioid addiction was viewed as a flaw of character and morality, treated as a psychiatric disorder, without any reliance on medication management. A series of publications that came from the "narcotic farm" treatment facilities in the 1960s and 1970s started to change how we view addiction - as a disease, not a failure of morals - and methadone maintenance programs at methadone clinics soon became the mainstay of opioid addiction treatment. $^{2}$ This changed with the Drug Addiction Treatment Act (DATA) of 2000 and the Food and Drug Administration's approval of two buprenorphine medications in 2002. Providers who received a waiver to prescribe buprenorphine could now do so from their outpatient practices.

Today, the stigma surrounding medication-assisted treatment (MAT) for opioid use disorder is still very real. But the notion that opioid use disorder is a chronic, relapsing, sociopsycho-biological disease has become more widely accepted. The former Surgeon General amplified the need to accept MAT as a standard of care in his 2016 report, "Facing Addiction in America: The Surgeon General's Report on Alcohol, Drugs, and Health."3 President Obama took a step towards expanding access to MAT in 2016 when he signed the Comprehensive Addiction and Recovery Act (CARA), and the newly passed SUPPORT Act advances these efforts further.

Yet providers remain hesitant to engage in opioid use disorder treatment with buprenorphine. Many providers continue to be intimidated by induction logistics as well as the unclear role of the Drug Enforcement Agency (DEA). ${ }^{4}$ The fact that the need for the DATA waiver was not eliminated altogether with this recent legislation is problematic in and of itself. This additional certification is unique in medicine. There is no requirement, for example, for a waiver to prescribe insulin for diabetes mellitus or a diuretic for hypertension. Additionally, this waiver is illogically required for the treatment of opioid use disorder, but not for prescription of the opioids that have been implicated in the surge of the epidemic.

\section{Where we go from here}

The SUPPORT Act does not come close to the expansive policy necessary to address an epidemic of this scale. For example, Nurse Practitioners (NPs) and Physician Assistants (PAs) - who are invaluable in treating opioid use disorder - still need to undergo extracurricular waiver training. As do physicians who graduated prior to this bill's passage and who are about to graduate from schools that do not have the training already incorporated in their standard curricula.

However, it does create a window for medical education to advance efforts to curb this epidemic. First and foremost, every medical school's office of medical education must ensure that their curricula include the necessary training so that every one of their students graduates eligible to receive their DATA waiver. It is the responsibility of medical schools to provide a broad, yet thorough curriculum on many topics, including hypertension and diabetes mellitus. Opioid use disorder should be no different. It is critical for medical schools to assert that opioid use disorder management must no longer be considered optional training. Teaching MAT for opioid use disorder cannot be prioritized any less than teaching the treatment of other chronic diseases. Medical schools across the country should commit to incorporating robust training into standard curricula, regardless of the specialty students intend to pursue.

In June 2018, more than 80 healthcare professionals from 29 medical schools across the United States met for a symposium at Brown University focused on best practices in teaching pain management, opioid prescribing, and substance use disorder treatment. ${ }^{5}$ Numerous initiatives were highlighted at this symposium, including the Warren Alpert Medical School of Brown University's unique partnership with the Rhode Island Board of Medical Licensure and Discipline to create a temporary, full physician license that can be attained by those who complete the standard medical school curriculum at Brown. The license type allows 2 nd and 3rd year residents to begin prescribing MAT during post-graduate training without going through the more standard DATA waiver training programs. Since that symposium, Arizona legislature approved Senate Bill 1029, ${ }^{6}$ which allows its allopathic and osteopathic boards to approve trainings, including medical school curricula, as sufficient for DATA-waiver eligibility. State-by-state arrangements like these may become unnecessary with the signing of the SUPPORT Act, but the curricula developed by these initiatives remain as important as ever.

We must seize this opportunity to unite as a medical community in order to address this issue in our curricula with the urgency it warrants. Every medical school must make it a priority to ensure that their standard curricula include the necessary material so that their training programs increase the number of graduates who are confident in their ability to prescribe MAT. 
Furthermore, curricula should include discussions of advocacy necessary to improve healthcare in this area. We need to prepare students to help eliminate the stigma that many experience when interfacing with healthcare. We need educational initiatives to support providers currently practicing who did not receive this training when they were in medical school. We need providers to advocate for naloxone to be available over the counter. And we must further explore, acknowledge, and address the racially-influenced history of policy impacting access to treatment for opioid use disorder. ${ }^{7}$

\section{Conclusion}

Although imperfect, we must play our part in maximizing the impact that the SUPPORT Act can have on curbing the opioid epidemic in the United States through medical education. We must continue to advocate for our ability to practice medicine unhindered by imperfect policies. And most importantly, we must step up to prepare every single healthcare practitioner to confidently care for those in need.

\section{Disclosure}

Dr George reports funding from an unrestricted grant from the Cardinal Health Foundation in support of this work.
The authors report no other conflicts of interest in this work.

\section{References}

1. 115th Congress. H.R.6 SUPPORT for Patients and Communities Act, Section 3202. Washington (DC): 115th Congress; 2018. Available from: https://www.congress.gov/bill/115th-congress/house-bill/6/text\#tocHE7D6B79AFB0447CD9D2F6F189A1586FE. Accessed July 10, 2019.

2. Joseph H, Woods JS. Changing the treatment direction for opiate addiction: Dr. Dole's research. Subst Use Misuse. 2018;53(2):181193. doi:10.1080/10826084.2017.1400069.

3. U.S. Department of Health and Human Services. Facing Addiction in America: The Surgeon General's Report on Alcohol, Drugs, and Health. Washington (DC); 2016. Available from: https://addiction.sur geongeneral.gov/sites/default/files/surgeon-generals-report.pdf. Accessed July 10, 2019.

4. Kissin W, McLeod C, Sonnefeld J, Stanton A. Experiences of a national sample of qualified addiction specialists who have and have not prescribed buprenorphine for opioid dependence. J Addict Dis. 2006;25(4):91-103. doi:10.1300/J069v25n04 09.

5. Cardinal Health Foundation. Brown university and the cardinal health foundation host opioid management curriculum development symposium. PR Newswire. Available from: https://www.prnewswire.com/ news-releases/brown-university-and-the-cardinal-health-foundationhost-opioid-management-curriculum-development-symposium300663937.html Accessed June 11, 2018.

6. Senate Bill 1029. Phoenix (AZ): State of Arizona; 2019. Available from: https://apps.azsos.gov/apps/publicservices/LegislativeFilings/ PDFs/2019/54th_Legislature_1st_Regular_Session/CH_182.pdf. Accessed July 10, 2019.

7. Hansen $\mathrm{H}$, Netherland J. Is the prescription opioid epidemic a white problem? Am J Public Health. 2016;106(12):2127-2129. doi:10.2105/ AJPH.2016.303483.
Advances in Medical Education and Practice is an international, peerreviewed, open access journal that aims to present and publish research on Medical Education covering medical, dental, nursing and allied health care professional education. The journal covers undergraduate education, postgraduate training and continuing medical education including emerging trends and innovative models linking education, research, and health care services. The manuscript management system is completely online and includes a very quick and fair peer-review system. Visit http://www.dovepress.com/testimonials.php to read real quotes from published authors. 